\title{
Climatology of the daily temperature range annual cycle in the United States
}

\author{
Daniel J. Leathers ${ }^{1, *}$, Michael A. Palecki ${ }^{2}$, David A. Robinson ${ }^{3}$, Kenneth F. Dewey ${ }^{2}$ \\ ${ }^{1}$ Center for Climatic Research, Department of Geography, University of Delaware, Newark, Delaware 19716-2541, USA \\ ${ }^{2}$ Meteorology/Climatology Program, Department of Geography, University of Nebraska-Lincoln, Lincoln, \\ Nebraska 68588-0135, USA \\ ${ }^{3}$ Department of Geography, Rutgers University, New Brunswick, New Jersey 08854, USA
}

\begin{abstract}
Many researchers are presently interested in detecting long-term trends in annual or seasonal daily temperature range (DTR), and attributing these changes to anthropogenic origins. However, very little work has been done to confirm the mechanisms that are important to determining the long-term average annual cycle of the DTR. Therefore, the focus of this work is to examine the spatial and temporal difference in the DTR average annual cycle across the United States, and to associate the patterns of these cycles with potential causal variables. Three major types of DTR annual cycle exist in the United States: high sun season maximum (northern and western U.S.), low sun season maximum (south central and southeast U.S.), and transitional season maxima (middle latitude in the U.S.). The annual cycles of the DTR in the northern and western U.S. are well related to average annual cycles of cloud cover and dew point temperature; only areas to the west of the Rocky Mountains have a strong linkage between DTR and precipitation frequency annual cycles. Across the northern tier of the U.S., the loss of snow cover is important to DTR transitions during the spring season. However, the onset of snow cover in the fall does not appear to be the major factor in DTR variations, which are instead more strongly associated with cloud cover effects. As expected from their sinusoidal annual cycle, maximum and minimum temperature cycles are linearly related to the DTR in regions with a warm season or cold season DTR maximum, while non-linear relationships exist where the DTR annual cycle has maxima in the transition seasons.
\end{abstract}

KEY WORDS: Daily temperature range - United States $\cdot$ Climate change

\section{INTRODUCTION}

In recent years much research has been directed toward the identification of potential changes that may be taking place within the global climate system. Scientists have been especially concerned with the possible ramifications of human induced atmospheric composition changes, particularly increases in 'greenhouse' gases such as $\mathrm{CO}_{2}$ and methane. Basic principles of atmospheric physics maintain that increases in the composition of such gases should lead to a general increase of lower tropospheric air temperature on a global scale (Kattenberg et al. 1996). Moreover, modeling studies suggests that such temperature changes may be asymmetrically reducing the diurnal cycle of temperature in

•E-mail: leathers@strauss.udel.edu many areas (e.g. Hansen et al. 1995, Mitchell et al. 1995). Specifically, increased evaporative cooling and cloud cover may cause a decrease in maximum daily temperatures and increases in minimum daily temperatures leading to detectable decreases in the diurnal temperature range (Cao et al. 1992).

Because of data availability and the theoretical linkage with climate variations attributable to atmospheric composition changes, daily temperature range (DTR) studies were some of the first conducted to identify possible human induced changes in the global climate system. Pioneering work was conducted by Karl et al. (1984) who documented decreases in the DTR in stations across the United States and Canada. Using a smaller set of stations, Karl et al. (1987) investigated the changes in the DTR in the context of cloudy versus clear sky conditions, finding substantial decreases in 
DTR over time during cloudy days of the same synoptic type. This initial work was later extended in Karl et al. (1991a, b). Although decreases in the DTR have been documented for many regions of the globe (Karl et al. 1993), the attribution of those changes to atmospheric composition changes is difficult. Many additional factors may play an important role in DTR changes at an individual station over time including urbanization, land use/land cover changes (Gallo et al. 1996), irrigation coverage changes, instrument changes, and station moves (Karl et al. 1993). Among these possible influences, the effects of urbanization have long been recognized as confounding the attribution of diurnal temperature range trends to atmospheric composition changes. As the population of an urban center increases, the structure of the diurnal temperature range at that location would be expected to shift in an asymmetric manner reducing the DTR primarily through increases in nighttime temperatures (Landsberg 1981, Gallo et al. 1996). The importance of urbanization has been discussed by several authors for a variety of locations (e.g. Cayan \& Douglas 1984, Karl et al. 1988, Karl \& Jones 1989, Jones et al. 1990). In addition, many authors have investigated the nature of DTR changes that may result from the other factors mentioned above (e.g. Quayle et al. 1991, Gall et al. 1992).

Although potential difficulties are inherent in the use of observational time series of daily temperature data for individual stations, many authors have conducted DTR studies for diverse regions of the globe. Studies discussing DTR trends have been published for China (Baker et al. 1995), the former Soviet Union (Razuvayev et al. 1995), the North Atlantic (Frich 1994), locations in Europe and Asia (Jones 1995), Australia and the southwest Pacific (Plummer et al. 1995, Salinger 1995) and the Nordic Countries (Kaas \& Frich 1995). Throughout many of these regions there is a strong tendency for decreased DTRs during most seasons of the year (Karl et al. 1993).

While these studies may consider the DTR on seasonal or annual time scales, few have considered the annual cycle of the DTR. Ruschy et al. (1991) investigated the average annual cycle of the DTR across Minnesota, USA. A primary finding of this study was the existence of abrupt discontinuities in the average annual cycle of the DTR during both the spring and especially the autumn seasons. These abrupt changes in the DTR were related to climatological cloud cover and snow cover changes, which in turn affect the net radiation. Robinson et al. (1995) used daily data from numerous sites across the United States to show that distinct average DTR annual cycles existed in diverse regions of the country. Although the authors advanced hypotheses regarding the 'climatological' forcing mechanisms that were responsible for the average DTR annual cycles, no quantitative relationships were reported. Finally, Schwartz (1996) examined the abrupt increases in the DTR that occur during the spring season. Using a limited number of stations stretching from the Great Plains to New England, USA, Schwartz (1996) showed a strong relationship between the rapid spring season DTR increases and snow cover loss, increased ceiling heights and more frequent southerly winds. Moreover, the author attributed the 'leveling off' of DTR increases several weeks into spring to increased plant transpiration to the lower troposphere during the period of phenological green-up.

In this research, the average annual cycle of the DTR across the United States will be investigated in a quantitative and detailed manner. A data set that includes 125 cooperative stations with 30-yr records of DTR data is combined with ancillary data from a 54 -member first order station network to better understand the characteristics of the DTR annual cycle and its relationship to diverse climate variables. The variables included in this study are cloud cover, dew point temperature, precipitation, maximum and minimum temperatures and snow cover. This research is based on the idea that a better understanding of the average annual cycle of the DTR is needed before the DTR can be effectively utilized as an indicator of global environmental change. Therefore, this work will concentrate on the climate system dynamics responsible for changes in the average annual cycle of the DTR, a topic that has to our knowledge not been discussed previously in the literature. The climate system dynamics responsible for normal DTR changes over the course of the annual cycle may in many cases be related to the long-term decreases in the DTR reported by several investigators. If this is the case, the observed changes in the DTR may be occurring due to changing climate system dynamics that are not directly attributable to human induced atmospheric composition changes. In the next section the data that is used in the study will be discussed. In Section 3 we will discuss the results of a regionalization of the average annual cycles of the DTR. The relationships between the annual cycles and various climatological variables will be investigated in Section 4. In the final section we will summarize our findings and offer conclusions.

\section{DATA AND METHODOLOGY}

Temperature is one of the most commonly abserved atmospheric variables. However, it is also a variable that is sensitive to many potential inhomogeneities when long time series of data are being studied. Problems often associated with long time series of daily 
data include the effects of urbanization, time of observation changes, station moves and instrument changes among others (Robinson 1993). In recent years much effort has been expended in the development of long-term, accurate, homogeneous temperature records that are vitally needed for studies of climate change and variability. The Historical Daily Climate Dataset (HDCD) was developed for such studies (Robinson 1993). To the extent possible, these are rural stations with a minimal number of station changes over the period of record. The HDCD includes observations of daily maximum and minimum temperature, precipitation, snowfall and snow depth. This dataset has been extensively quality controlled, and any data that do not meet a rigorous set of queries are flagged with appropriate warnings for the user. In this study, we utilize maximum and minimum temperature, precipitation and snow cover data from a 125-station subset of the HDCD distributed homogeneously across the coterminous United States (Fig. 1a). Thirty-year averages of relevant daily values of variables are calculated for the period 1959 through 1988.

Ancillary cloud cover and dew point temperature data are collected from the SAMPSON data set (NCDC 1993) for a 54 -station network that is, to the extent possible, geographically co-located with stations from the HDCD (Fig. 1b). This
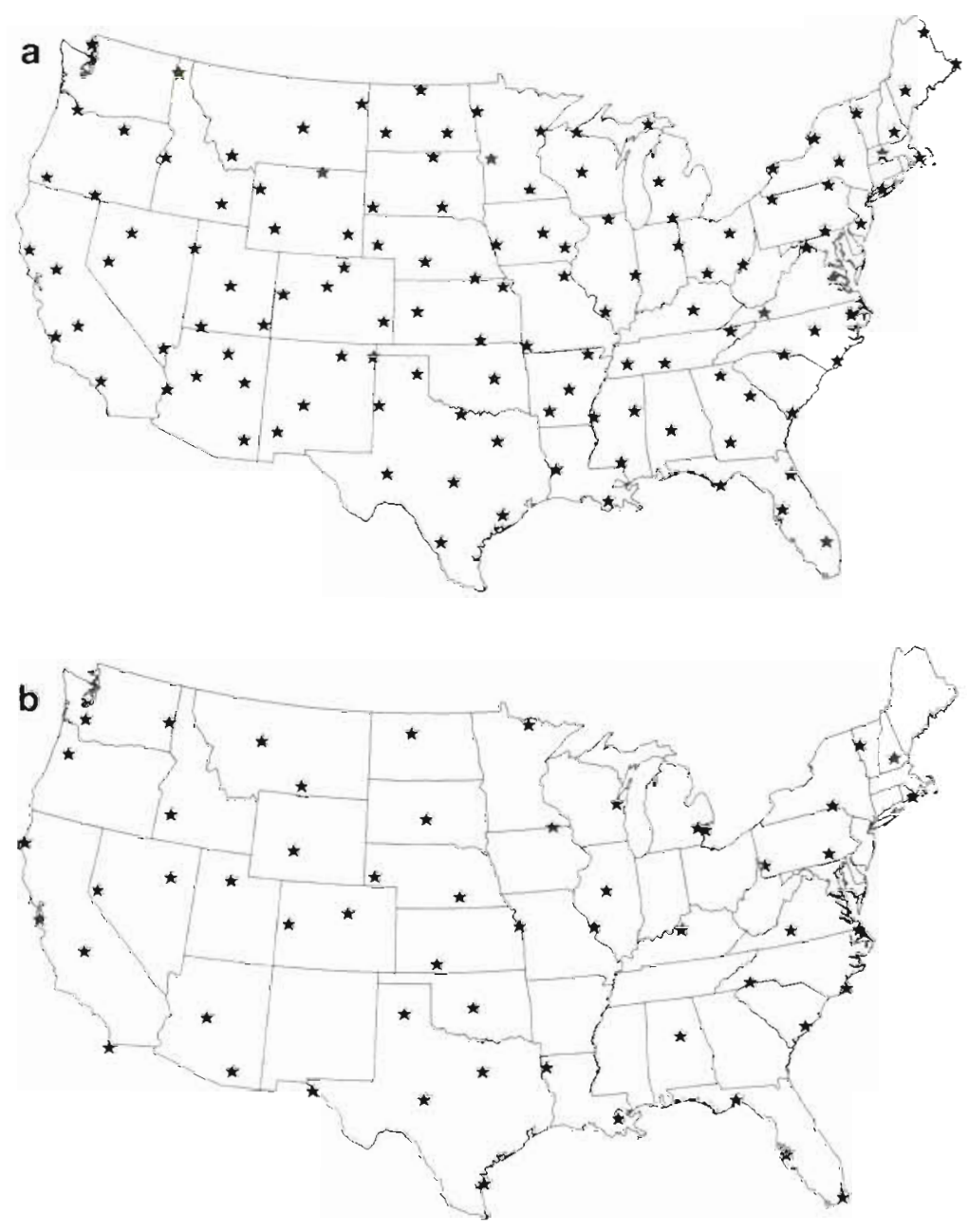

Fig. 1. (a) 125-station subset of the Historical Daily Climate Data set used in this study and (b) 54-station network of ancillary data (cloud cover and dew point temperature) in the U.S.

dataset contains hourly data from

National Weather Service (NWS) first-order weather stations and covers the period from 1961 through 1990. Thirty-year averages of daily cloud cover and dew point temperature are calculated using all available hourly measurements for each day.

\section{DTR AVERAGE ANNUAL CYCLE REGIONALIZATION}

DTR average annual cycles from Burlington, Vermont, Gothenberg, Nebraska, and Willcox, Arizona, are shown in Fig. 2. It is clear from these examples that the annual cycle of DTR varies dramatically across the country. In many locations the DTR undergoes rapid variations within narrow temporal windows of the annual cycle. The abrupt changes are so large as to indicate the simultaneous timing of these transitions during a preponderance of the 30 years contained within the record. For example, in Willcox, the DTR drops from a maximum of approximately $24^{\circ} \mathrm{C}$ at the beginning of July to a minimum of approximately $16^{\circ} \mathrm{C}$ over a 3 wk period (Fig. 2a). Robinson et al. (1995) attributed this dramatic decrease to the initiation of the southwest summer monsoon. In Burlington, 2 rapid transitions take place in the annual cycle of the DTR (Fig. 2b). The DTR increases over a $2 \mathrm{wk}$ period in early April from a value of approximately $9^{\circ} \mathrm{C}$ to a value of $13^{\circ} \mathrm{C}$. During autumn, at the beginning of November, a rapid drop of approximately the same magnitude occurs in the DTR over a similar time interval. These transitions have been attributed to a loss of snow cover in April and an increase in cloud cover in the autumn (Robinson et al. 1995). Gothenberg evidences no rapid transitions in DTR over the course of the annual cycle. Instead, slow transitions lead to a 

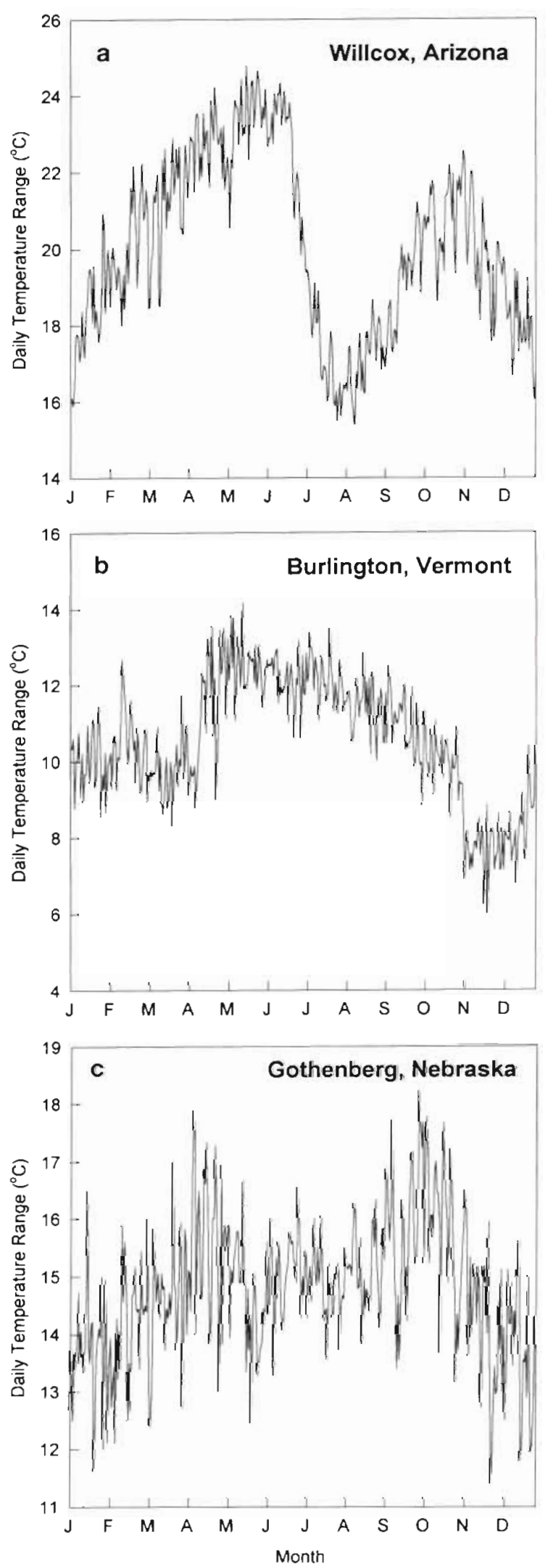

Fig. 2. Average DTR annual cycles for (a) Willcox, Arizona, (b) Burlington, Vermont and (c) Gothenberg, Nebraska, USA double peak in DTR during the spring and autumn months (Fig. 2c). Despite the differing modes of transition, both Willcox and Gothenberg display semiannual maxima in the transition seasons. It is likely that several diverse physical processes are at work which cause average annual cycles of the DTR to vary across diverse regions of the United States.

In order to better understand the nature of spatial variations in the DTR average annual cycle, principal component analysis (PCA) and clustering techniques are applied to the annual cycles. The PCA is performed on daily time series of the mean temperature range for a network of 125 stations. Thus the data matrix is 125 (stations) $\times 365$ (days). The PCA extracts 5 major components which account for $78.6 \%$ of the variation of the total data matrix. The number of principal components retained for analysis is based on an inspection of the scree slope (Cattell 1966). The component loadings for each station are obtained by calculating the correlation between each station and the individual components. Stations that are in close geographic proximity tend to have similar loadings on individual components. Wards' clustering algorithm is applied to group stations with similar component loadings into distinct, homogeneous spatial groupings.

Two solutions from the clustering procedure are retained for further analysis. A 3-cluster solution is chosen that divides the United States into 3 spatially homogeneous geographic regions (Fig. 3a). Although there are certainly more than 3 distinct DTR annual cycle types found across the country, the 3 -cluster solution is retained because of its simplicity and its ability to isolate the major differences between diverse sections of the United States. In addition, an 8-cluster solution is retained which divides the country into additional subregions, with distinct annual cycles (Fig. 3b). The subregions identified in the 8 -cluster solution are each a part of one of the larger clusters from the 3-cluster solution described above. Therefore, the sub-regions will be designated by their membership in one of the regions from the 3 -cluster solution, and by an additional letter indicating their respective sub-region derived from the 8 -cluster solution (see Fig. 3b).

Region 1 encompasses the entire northern tier of the United States from Maine westward to Washington, most of the intermountain west, and Pacific Coast. DTR annual cycles from the 2 sub-regions within region 1 are shown in Fig. 4. Big Rapids, Michigan (Fig. 4a) and Sacramento, California (Fig. 4 b) have broadly similar DTR annual cycles with the maximum DTR occurring during the high sun months and minimum DTR occurring during the period from late autumn through early spring. A generally similar shape was also evident in the DTR annual cycle from Burlington, Vermont (Fig. $2 b$ ), which is in the same region. The major difference 

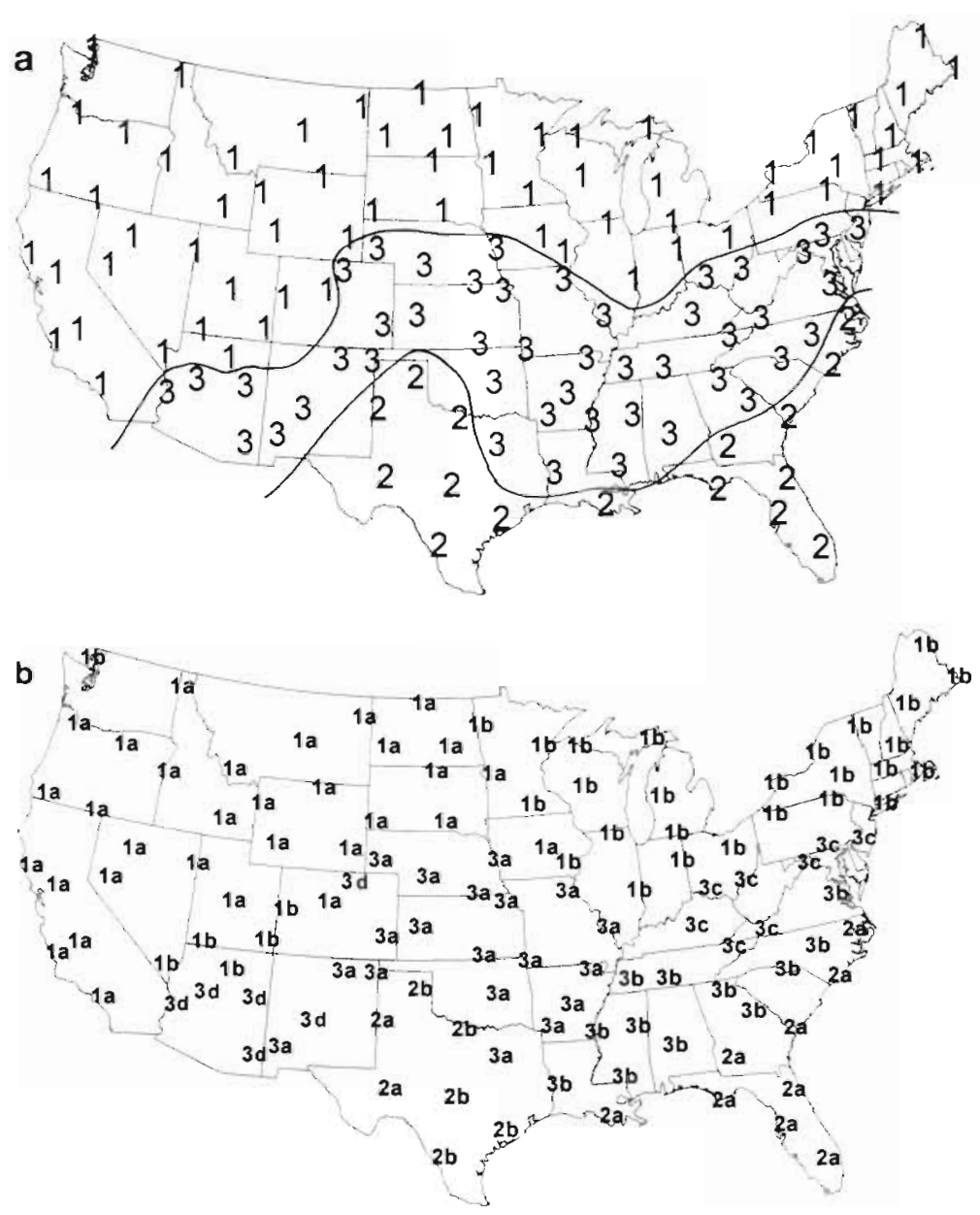

Fig. 3. Results of (a) 3-cluster solution and (b) 8-cluster solution defining average DTR annual cycle types across the coterminous United States

across region $2 \mathrm{~b}$ in the spring and an earlier increase in DTR magnitude in the autumn, compared to sub-region 2a. Also, a local maximum in DTR occurs during the late summer in eastern Texas (region 2b) which is not found in region $2 \mathrm{a}$.

Region 3 covers locations across the latitudinal center of the country from the mid-Atlantic, westward through the Great Plains and into the southwest United States. Stations in this area show a more complicated 2-peak maximum DTR structure as evidenced by the stations representing the 4 sub-regions that comprise region 3 (Fig. 6a-d). The central Great Plains and Midwest portion of the country are covered by sub-region $3 \mathrm{a}$ (e.g. Horton, Kansas; Fig. 6a). In this region, a weak spring and autumn season peak in the DTR is evident, with the lowest DTR values found during the winter season. Subregion $3 \mathrm{~b}$ covers portions of the southcentral United States and is represented by State University, Mississippi (Fig. 6b). In this area, the summer minimum in DTR is more pronounced and the autumn peak in the DTR is more evident than the spring peak. Across the Ohio Valley and midAtlantic in sub-region $3 c$, DTR values reach a distinct minimum during the winter months, and peak relatively strongly during the spring and autumn seasons. A local minimum in DTR is found during the summer in Danville, Kentucky (Fig. 6c).

between sub-regions $1 \mathrm{a}$ and $1 \mathrm{~b}$ is in the shape of the DTR annual cycle. In sub-region $1 \mathrm{a}$ (Fig. 4b), the DTR annual cycle has a strong peak during the high sun months, with relatively smooth increases in DTR during the spring and decreases during the autumn months. In sub-region 1b (Fig. $4 \mathrm{a}$ ), the peak during the high sun months is not as strong, and rather abrupt transitions in DTR take place during both the spring and autumn months (see especially Burlington, Vermont, Fig. 2b).

Region 2 includes locations in the southern tier of the United States from Texas, eastward to the Atlantic Coast south of Cape Hatteras, North Carolina. In this region the character of the annual cycle of DTR is opposite to Region 1. DTR annual cycles from Belle Glade, Florida (sub-region 2a, Fig. 5a) and Pierce, Texas (subregion 2 b. Fig. 5 b) show a minimum DTR during the high sur months and a maximum DTR during the winter season (Fig. 5a, b). All stations in region 2 evidence the same general pattern of minimum DTR values during the high sun months. The major difference between sub-regions $2 a$ and $2 b$ is an earlier decrease in the DTR
Stations comprising region $3 \mathrm{~d}$, represented by Willcox, Arizona, show a very dramatic drop in DTR from a peak in early summer to the lowest values of the year during the late summer (Fig. 6d), likely related to the onset of the southwest monsoon (Robinson et al. 1995). DTR values increase again throughout the autumn, but then decrease in magnitude during the winter season. Although there are distinct regional differences in the DTR annual cycles across region 3 , all stations in the region evidence a DTR peak during the spring and autumn seasons and minimum values of DTR during the low sun months.

\section{DTR AVERAGE ANNUAL CYCLE ASSOCIA- TIONS WITH CLIMATE VARIABLES}

\subsection{Moisture variables}

In order to better understand the climate system variables that are associated with the patterns of the 

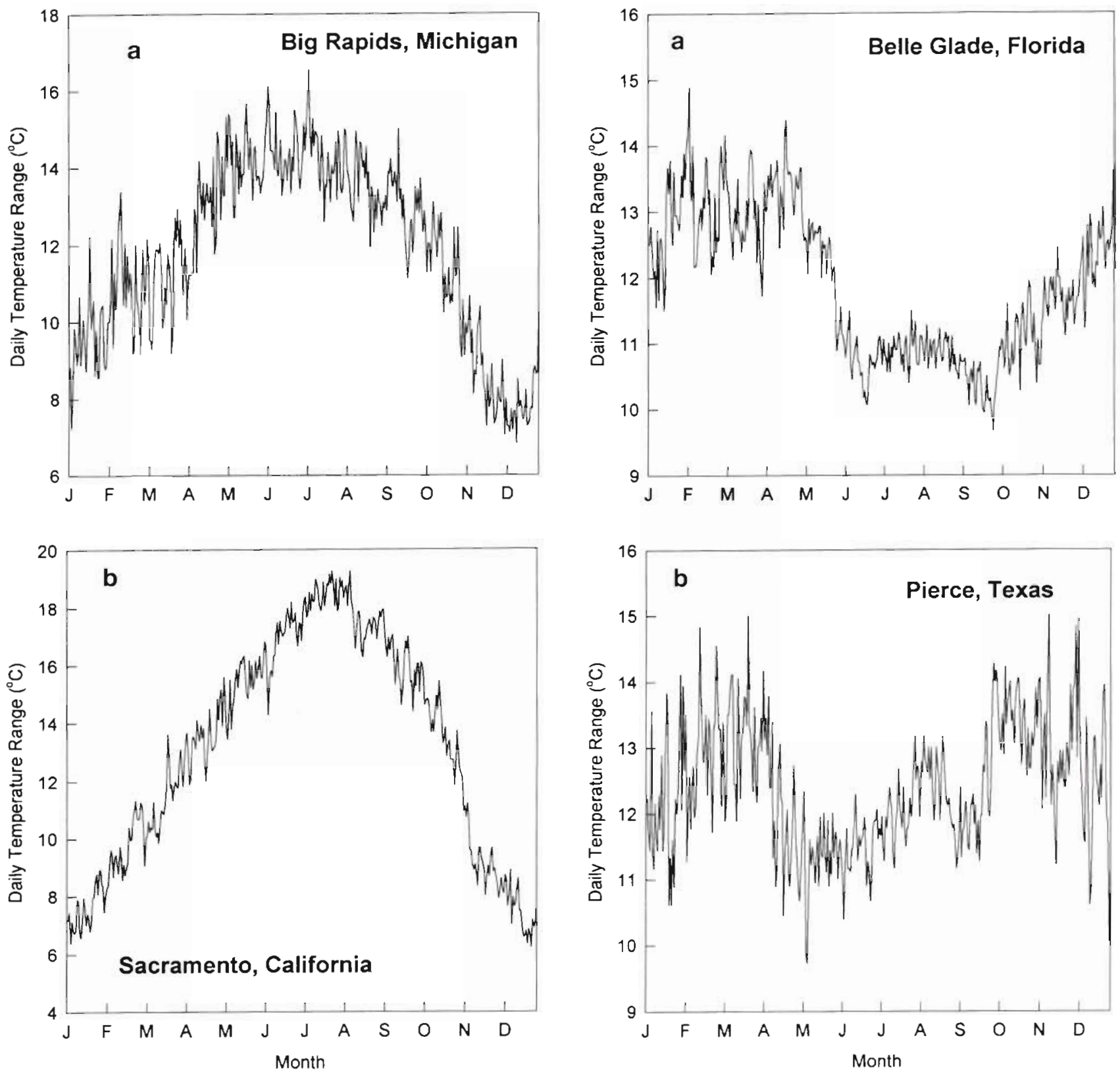

Fig. 4. Average DTR annual cycles for (a) Big Rapids, Michigan and (b) Sacramento, California, USA

DTR average annual cycles, regression analyses were performed relating the DTR data and ancillary data from the 54-station network discussed above. It is hypothesized that moisture variables should play a significant role in the changing character of DTR over the course of the annual cycle. Thus, 3 moisture variables were investigated for their association with the DTR annual cycle: cloud cover, dew point temperature and precipitation frequency.

Cloud cover is an atmospheric variable that is known to affect the magnitude of the DTR (Karl et al. 1987). The

Fig. 5. Average DTR annual cycles for (a) Belle Glade, Florida and (b) Pierce, Texas, USA

presence of cloud cover would act to depress daytime high temperatures because of decreased receipt of solar radiation at the earth's surface. During the nighttime hours, the presence of clouds should act to increase the low temperature due to the effects of counter radiation. Taken together, the effect of increased cloud cover should be to decrease the DTR. A lack of cloud cover acts in an opposite manner, increasing the DTR.

The radiative characteristics of the atmosphere are also important in the magnitude of the DTR. The surface dew point temperature is an excellent measure of 

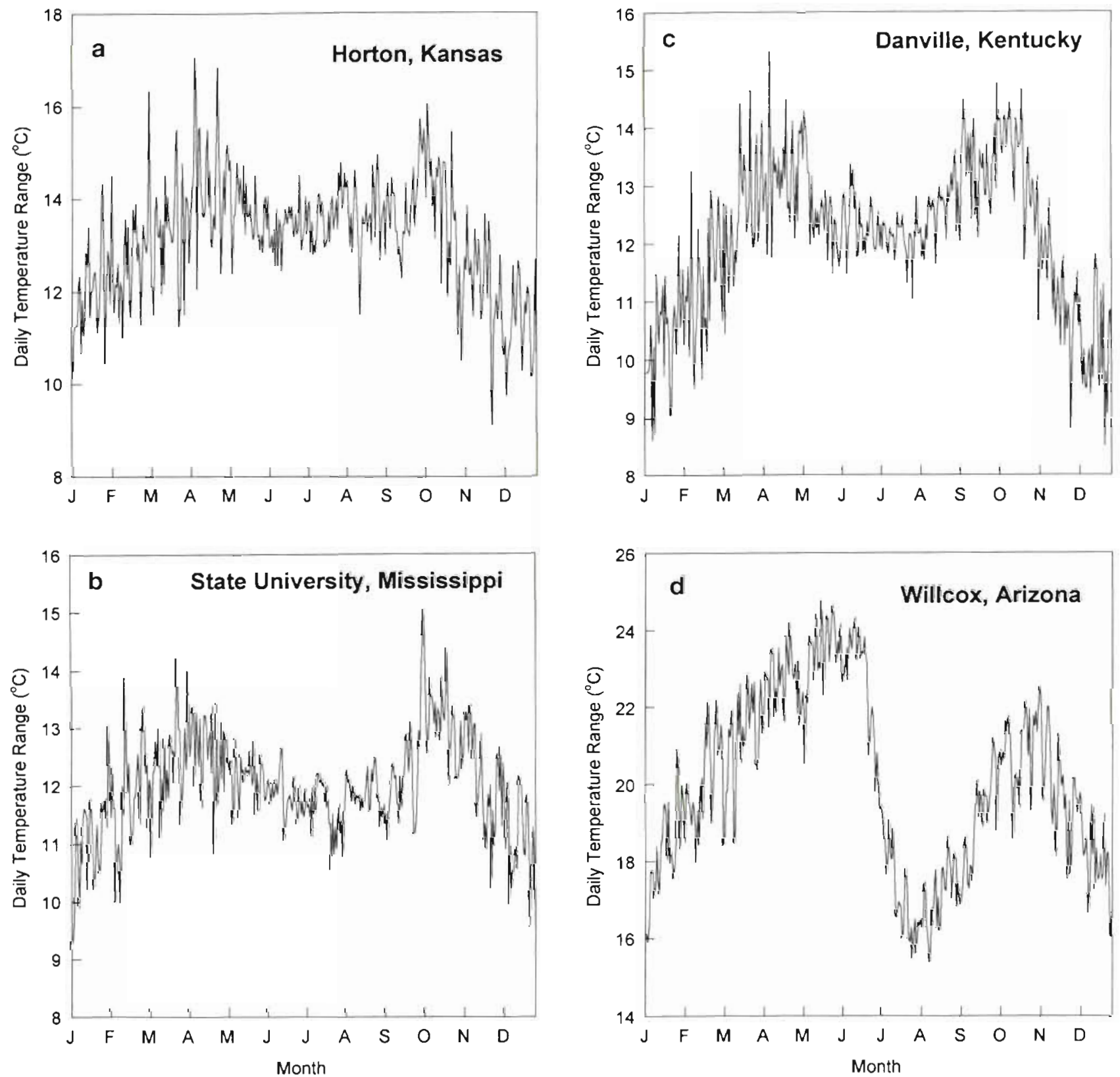

Fig. 6. Average DTR annual cycles for (a) Horton, Kansas, (b) State University, Mississippi, (c) Danville, Kentucky and (d) Willcox, Arizona, USA

the amount of water vapor present in the lower atmosphere. Large dew point values should act to increase nighttime low temperatures because of the radiative effects of atmospheric water vapor, increasing the magnitude of radiation absorbed by the atmosphere and subsequently the magnitude of radiation remitted to the earth's surface. Thus, the presence of high dew point temperatures at night should act to decrease the DTR. Finally, the association between the annual cycles of DTR and precipitation frequency was explored to better understand the relationship between precipitation seasons and the DTR. To complete the analysis, mean annual cycles of cloud cover, dew point temperature and precipitation frequency were derived for each station for the 30 yr period 1961 through 1990 . These mean annual cycles were regressed against the mean annual cycles of DTR for stations that are closely collocated with ancillary data sites. The regression analysis is completed using a first-order linear regression algorithm.

Fig. 7 a displays explained variance values $\left(R^{2}\right)$ for the association between the DTR and the daily cloud 

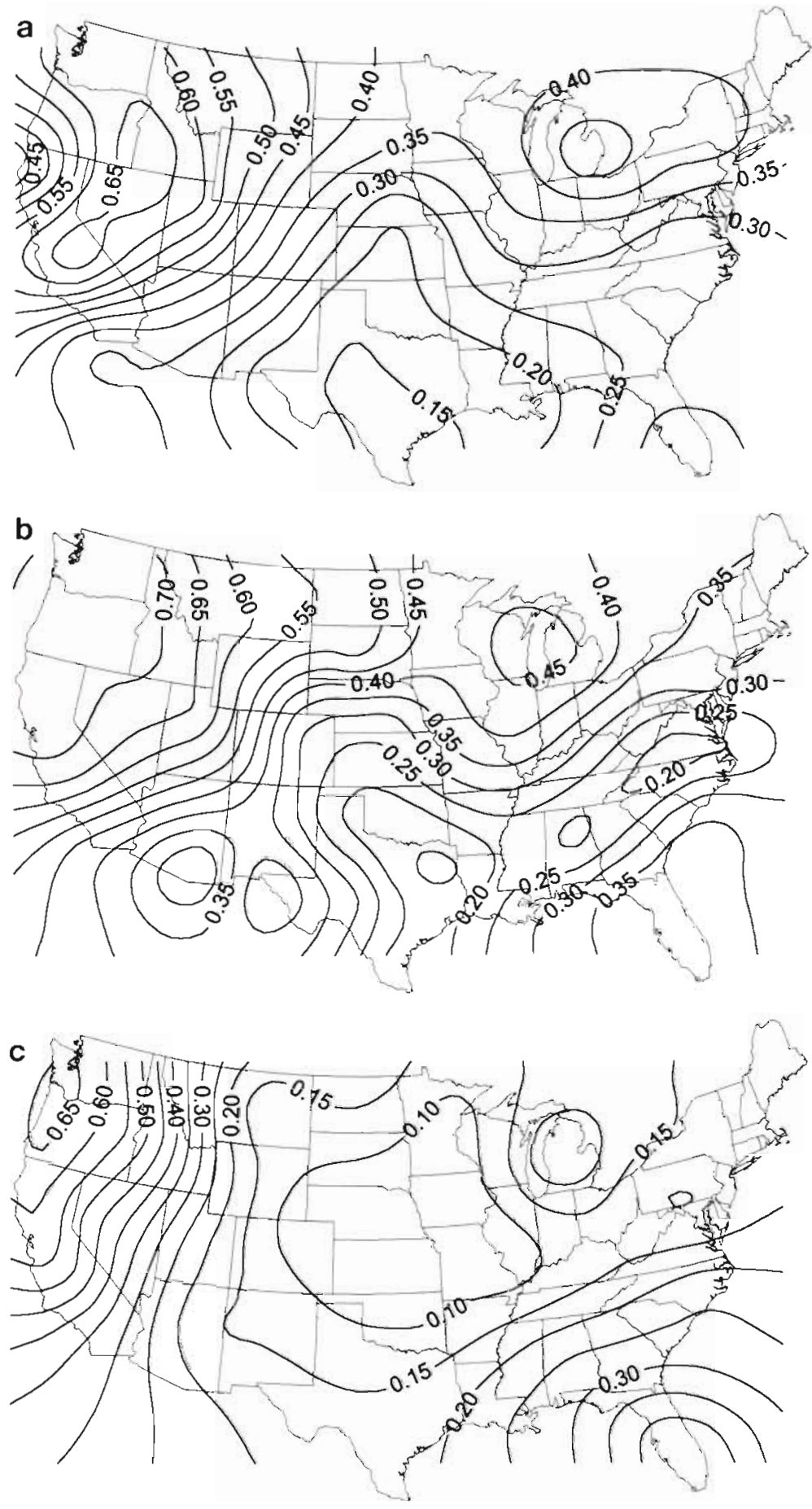

Fig. 7. Explained variance $\left(\mathrm{R}^{2}\right)$ values for the relationship between (a) average daily DTR and average daily cloud cover, (b) average daily DTR and average daily dew point temperature and (c) average daily DTR and average daily precipitation frequency

cover. In general, the association between cloud cover and the DTR is greatest in the western United States, especially in the Great Basin region. The weakest relationships exist across the southern portion of the Great
Plains and Texas. The association is also relatively large across the eastern Great Lakes, and the northeast United States. It is important to note that the areas with the largest DTR/cloud cover association are contained in Region 1 in the DTR regionalization discussed above. The relationship between cloud cover and DTR for Boise, Idaho is shown in Fig. 8a. In Boise, the DTR peaks in late summer with maximum DTR values as large as $23^{\circ} \mathrm{C}$. At this same time cloud cover values reach a minimum, with mean daily cloud cover values as low as $2 / 10$ coverage. The relationship between cloud cover and DTR in Boise is linear in character (Fig. 8b) and quite strong. All DTR/cloud cover scatter plots for the 54 -stations tested had a general linear nature to the relationship. Thus, the areas contained in Region 1 of the DTR regionalization seem to have an annual cycle associated with the cloud cover climatology of the area. During high sun months, when cloud cover is generally at a minimum, maximum values of daily temperature range are found across the northern tier of the country. During the low sun months cloud cover in most of these areas increases dramatically in association with a decrease in DTR.

A similar pattern of association is seen between the DTR and dew point temperature annual cycles (Fig. 7b). Maximum values of $\mathrm{R}^{2}$ are found in the northwest United States indicating a strong linear association between the DTR and atmospheric moisture content in this area. The association is weakest from eastern Texas through the Carolinas. Similarly to cloud cover, explained variance values are also relatively high in the northern tier of states.

The spatial characteristics of the association between the annual cycle of the DTR and the annual cycle of precipitation frequency are different from those observed for cloud cover or dew point temperature (Fig. 7c). There is a very weak association between DTR values and precipitation frequency across a large section of the United States from the high plains to the Atlantic Coast. Maximum $\mathrm{R}^{2}$ values are found from the western slopes of the Rocky Mountains westward to the Pacific Ocean, with the largest values found along coastal sections of Oregon and Washington. In addition, relatively 

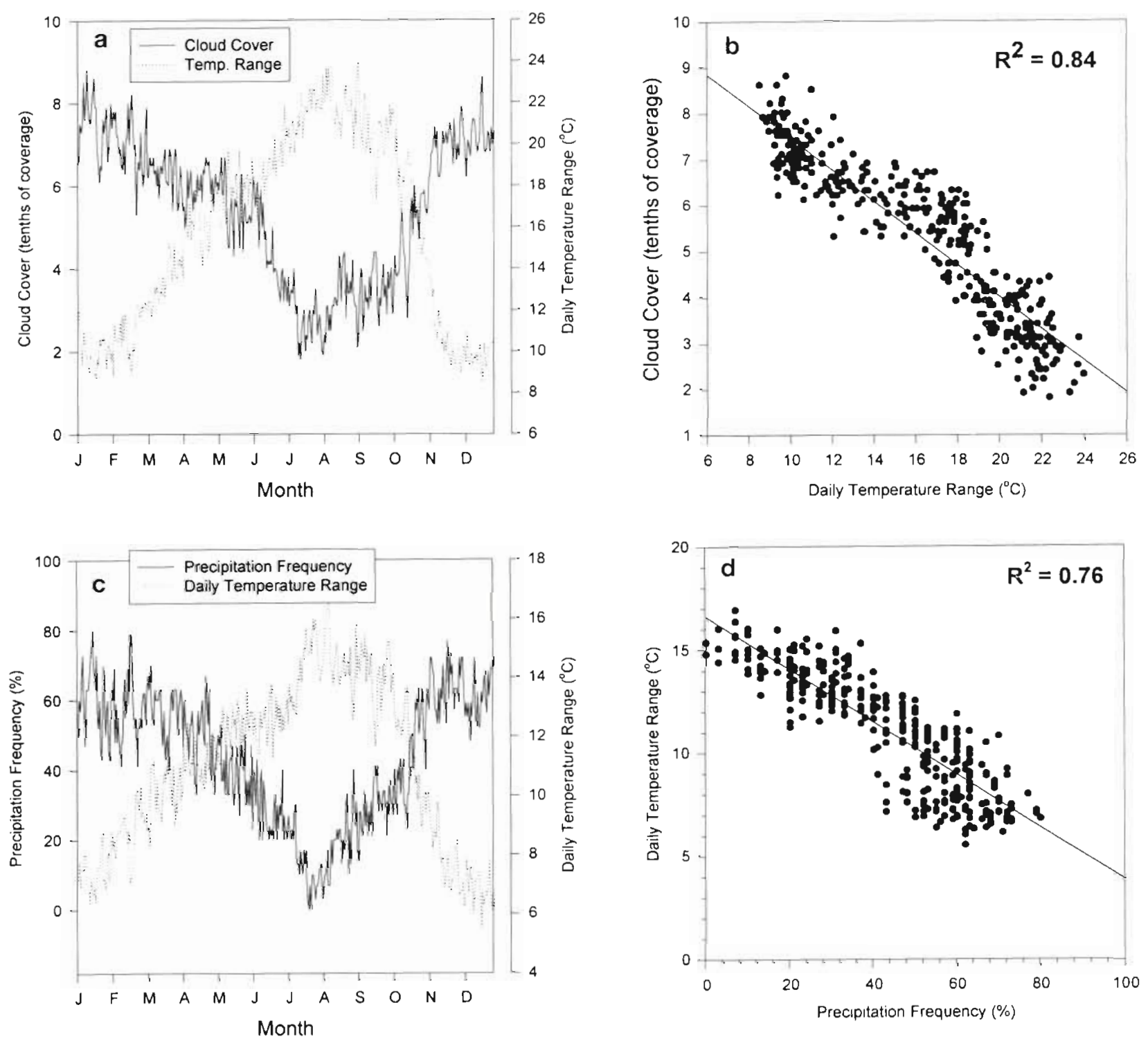

Fig. 8. (a) Time series of average DTR and average cloud cover and (b) scatterplot of the same variables for Boise, Idaho. (c) Time series of average DTR and average precipitation frequency and (d) scatterplot of the same variables for Vancouver, Washington

high association values are found across the Florida peninsula. Fig. 8c shows the annual cycle of the DTR and the precipitation frequency for Vancouver, Washington. It is clear that the maximum DTR occurs during the 'dry season' when precipitation frequencies are less than $10 \%$ and that the minimum DTR occurs during the 'wet season' when precipitation frequencies are above $50 \%$. The relationship between the two is linear, as it is for other stations in the western portion of the country (Fig. 8d). Therefore, across the western portion of the United States, the DTR annual cycle varies with the precipitation season.

Taken as a whole, moisture variables are clearly important in the annual cycle of the DTR. However, their importance is spatially specific. Cloud cover is most important across the northern tier and the western one-third of the United States, in areas where vagaries in the seasonal position of the circumpolar vortex are very important in determining the amount of cloud cover. In the southern portion of the country, DTR/cloud cover associations are much weaker. Dew point temperature associations with the DTR are generally stronger than those of cloud cover. Again, the western one-third of the country, and to a lesser extent the northern tier, evidence the strongest relationships. Finally, the association between the DTR and the precipitation frequency is strong only west of the Rocky Mountains and across the Florida peninsula. 

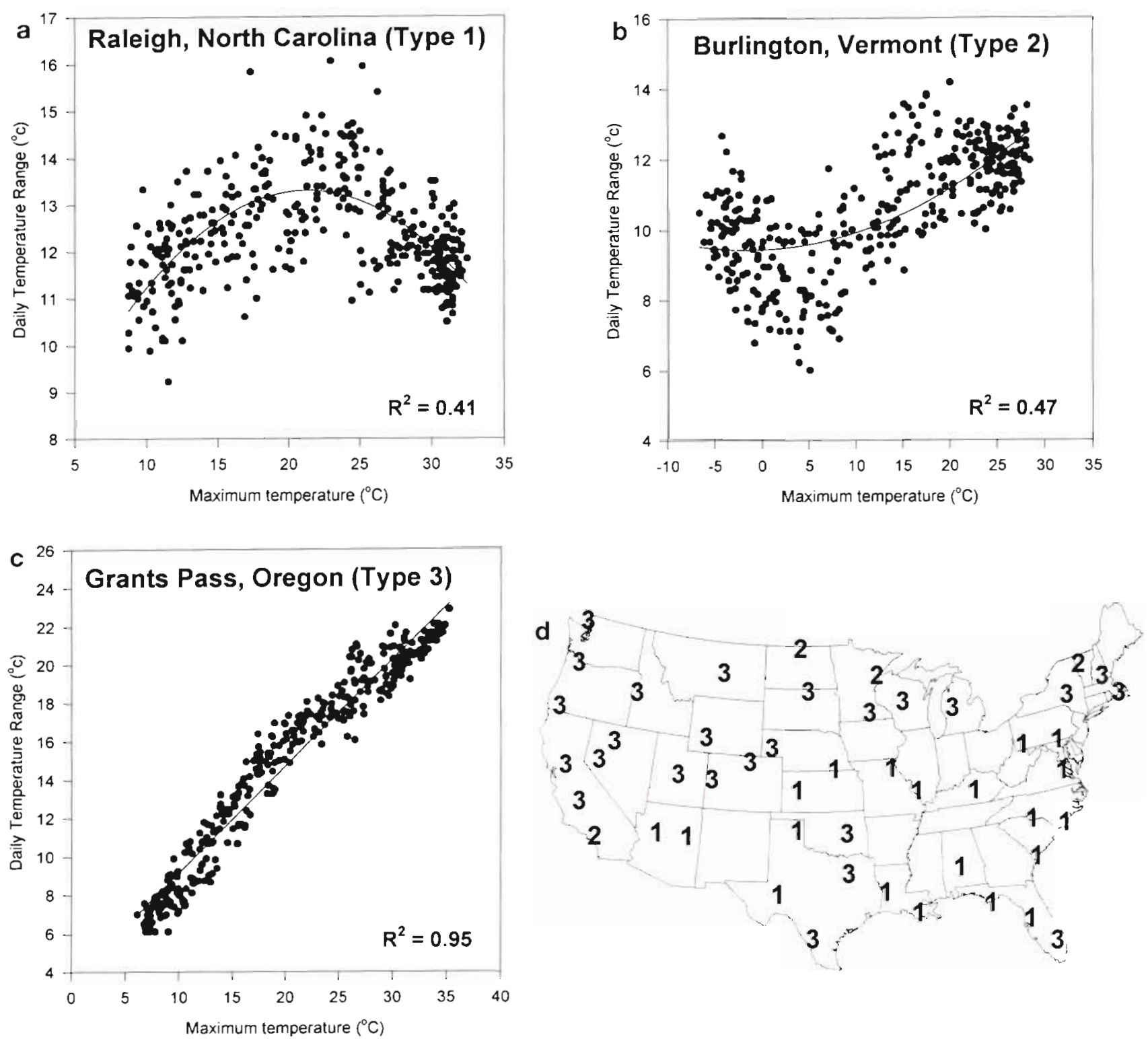

Fig. 9. Scatterplot of average DTR versus average maximum temperature for (a) Raleigh, North Carolina, (b) Burlington, Vermont and (c) Grants Pass, Oregon. (d) Spatial distribution of average DTR/temperature relationship types across the coterminous United States: 1 = downward parabola, $2=$ upward parabola, $3=$ linear

\subsection{Temperature variables}

The annual cycles of daily maximum and minimum temperature must also be strongly associated with the annual cycle of the DTR. To investigate this hypothesis, the annual cycle of the DTR was regressed against the daily maximum and minimum temperature means for a subset of the 125-station network discussed above. Fig. $9 a-c$ shows scatter plots of the annual cycle of maximum temperature versus the annual cycle of the DTR for Raleigh, North Carolina, Burlington, Vermont and Grants Pass, Oregon. It is clear that the rela- tionship between these 2 variables is non-linear in many cases. In fact, the analysis indicates that there are 3 major types of relationships between the DTR and maximum temperature annual cycles (DTR/minimum temperature relationships are similar to those of maximum temperature). Raleigh, North Carolina shows a downward turned parabola that indicates that values of the DTR are at a minimum when daily maximum temperatures are at either extreme during the annual cycle (Fig. 9a). Thus, Raleigh experiences its highest DTR values during the transition seasons of spring and autumn. This same result was discussed in 
Section 3. At Burlington (Fig. 9b), DTR values generally reach maximum values during either extreme in the maximum temperatures, but most commonly during the high sun months when maximum temperatures are at their highest. Finally, at Grants Pass, the annual cycle of the DTR and the maximum temperature evidence a generally linear relationship, with maximum (minimum) DTR occurring during times of the highest (lowest) maximum temperature (Fig. 9c).

Fig. 9d shows a map that lists the type of relationship that exists between the annual cycle of the maximum/minimum temperature and the annual cycle of the DTR. Many stations in the central and southern latitudes of the eastern United States show a downward parabolic relationship similar to Raleigh (Fig. 9a). Thus, at these stations the maximum DTR is typically occurring during the transition seasons, while minimum values of the DTR occur during the temperature extremes in the annual cycle (most commonly during summer). In the southern portion of this region, the lowest DTR values are clearly associated with the highest maximum and minimum temperatures. The upward parabolic relationship is considerably rare, with stations along the extreme northern tier of the eastern United States demonstrating a pattern similar to Burlington (Fig. 9b). In each case, these stations have their maximum DTR during the extreme phases of the annual cycle, with the largest values found during the high sun months. Finally, the more linear relationships between DTR and maximum temperature are found across the western United States, the upper Midwest and even in the Northeast. In addition, some stations in the southeastern portion of the country also have nearly linear relationships. However, the linear relationships found in Florida, Texas and Oklahoma are negative relationships, meaning that the largest DTR values occur during the cold season and the smallest values during the warm season.

A second-order polynomial regression was utilized to gauge the relationship between the DTR average annual cycle and the mean maximum (minimum) temperature annual cycle for those stations that evidenced non-linear relationships, while linear regressive techniques were used for stations with linear relationships. Fig. 10a displays the association between the annual cycles of the DTR and the maximum temperature,
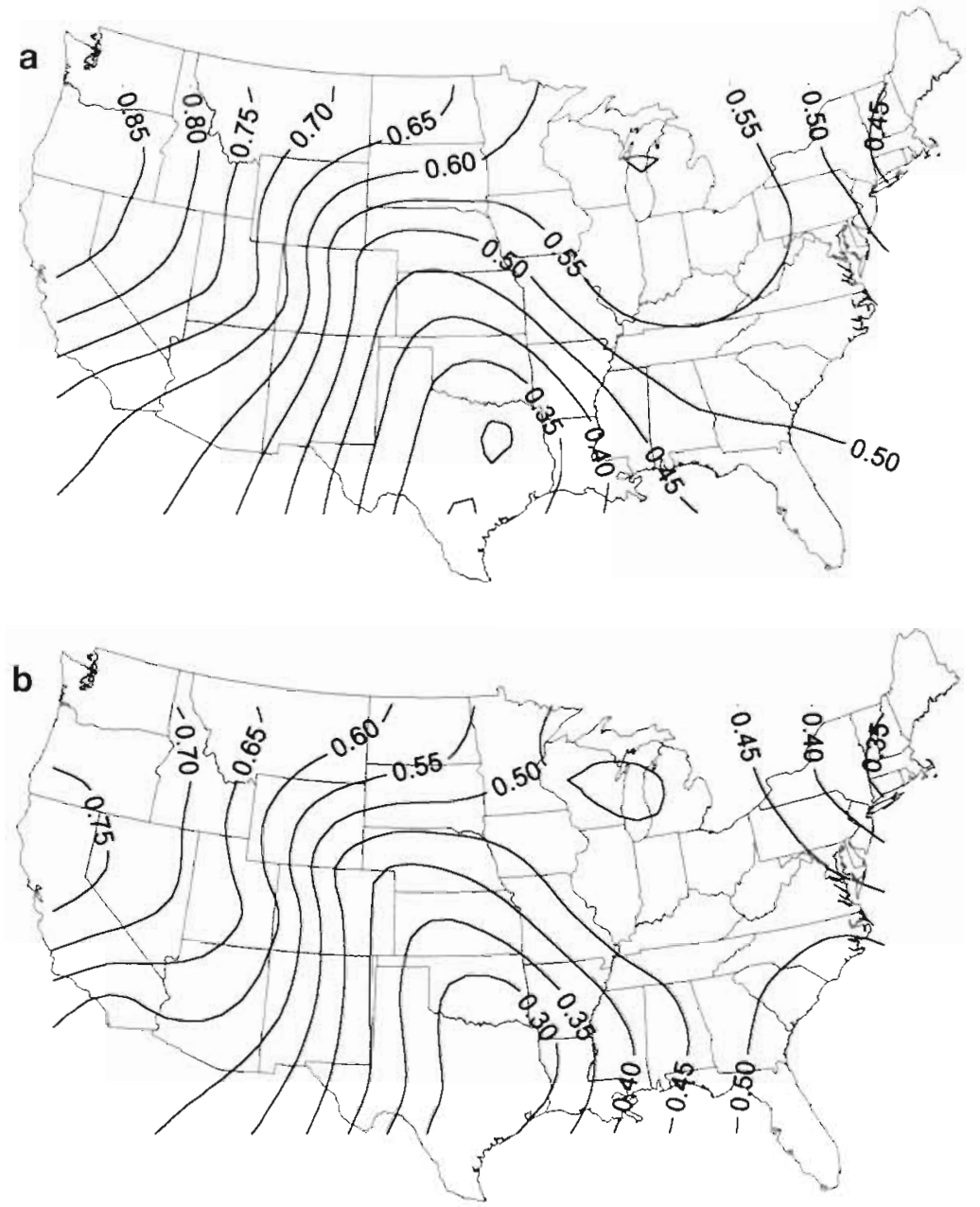

Fig. 10. Explained variance $\left(R^{2}\right)$ values for the relationship between average DTR and: (a) average maximum temperature and (b) average minimum temperature while Fig. 10 b shows the same for minimum temperature. The 2 maps are very similar, as both maximum and minimum temperatures follow a simple sinusoidal pattern. The association between the DTR and maximum and/or minimum temperature is most evident in the western portion of the country where linear relationships dominate the association. This is clearly due to the obvious sinusoidal pattern of DTR seen in the stations of DTR regional class 1 . Values of $R^{2}$ reach a minimum across the southern Great Plains, in an area where the relationship was gauged to be linear in character but negative. An additional area of low correlation values is found across the northeastern portion of the country. In most areas, and for the country as a whole, maximum temperatures explain somewhat more variance in the DTR than minimum temperatures.

As a whole, the relationship between the DTR and the maximum and minimum temperatures is quite 

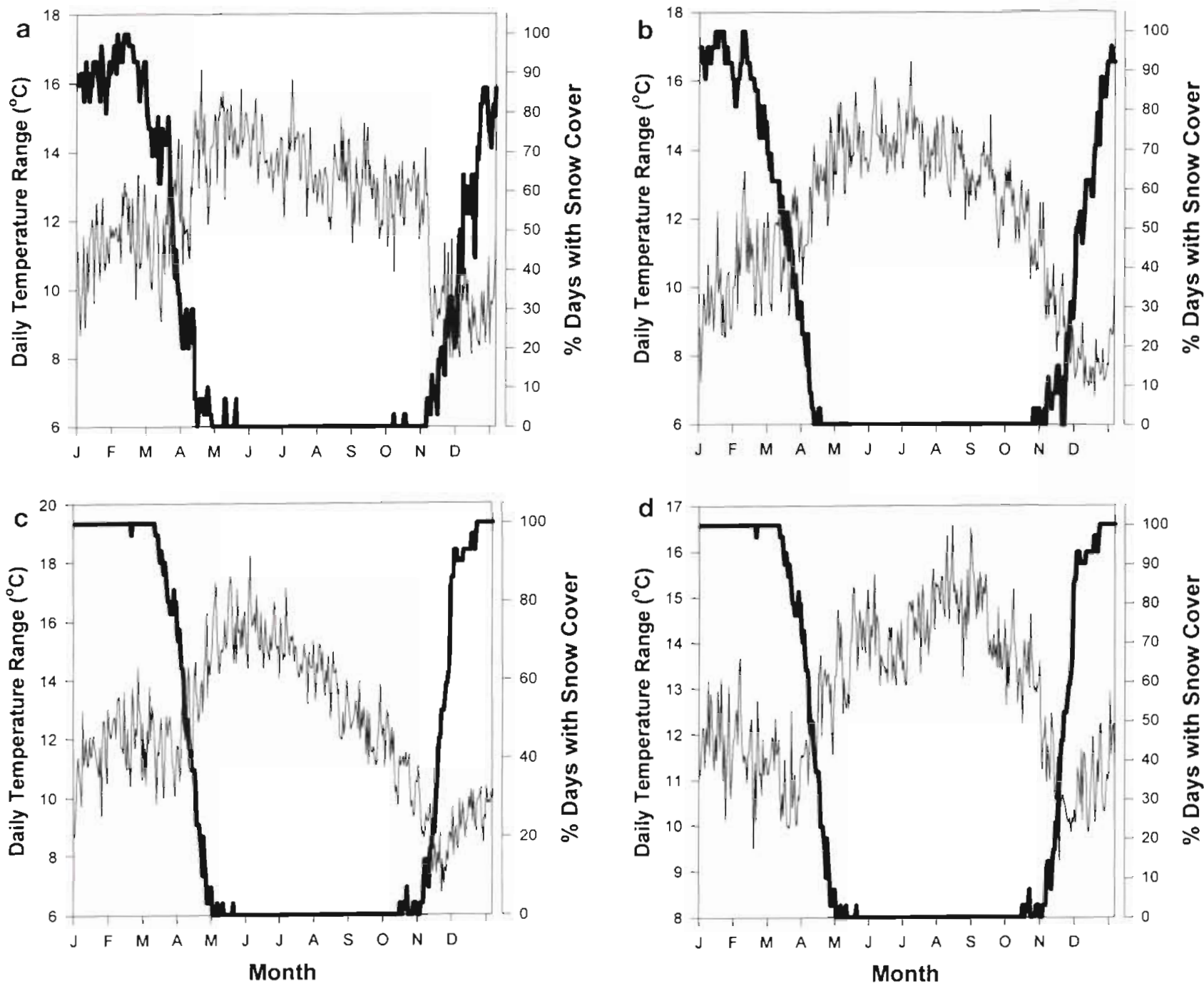

Fig. 11. Times series of average DTR (thin line) and percentage of days with snow cover (thick line) for (a) Cooperstown, New York, (b) Big Rapids, Michigan, (c) Cloquet, Minnesota and (d) Bottineau, North Dakota

complicated, being both spatially and temporally specific. Across the extreme northern tier of the country, the relationship takes the shape of an upward turned parabola, with maximum DTR values occurring during the extremes in the annual cycle, especially during the high sun months. Across much of the northern and western portions of the United States, the relationships are linear with maximum DTR values found during the warmest period of the year. Over much of the middle and southern portions of the country the relationship is downward parabolic, with maximum values of the DTR occurring during the transition seasons. Finally, a small portion of stations in Florida and Texas exhibit nearly linear relationships of a negative sign indicating that DTR values peak during the coldest portion of the year

\subsection{Snow cover}

The data analyzed in this study indicate an observed minimum in the DTR during the cold season across the northern half of the United States. At many stations, decreases in the DTR take place abruptly during the autumn season and increases in the DTR occur abruptly in the early spring (see Fig. 2b). This same tendency was reported by Ruschy et al. (1991) for a suite of stations in Minnesota and by Schwartz (1996) for stations from the Great Plains to New England. Snow cover is a cold season variable that has been shown to affect the DTR (Baker et al. 1992, Leathers et al. 1995, Schwartz 1996). During the day, snow cover affects the surface radiation balance through its high albedo. Incoming solar radiation that would normally 
be absorbed at the earth's surface is reflected away, decreasing the daily maximum temperature. At night, snow cover has also been shown to be associated with a decrease in the minimum temperature (Baker et al. 1992, Leathers et al. 1995). However, this longwaveinduced radiative effect is not as strong as the shortwave effects of the daylight hours, resulting in a larger temperature depression during the day than at right, thus reducing the DTR.

Fig. $11 \mathrm{a}-\mathrm{d}$ shows time series of the percentage of days with snow cover plotted with the DTR for Cooperstown, New York; Big Rapids, Michigan; Cloquet, Minnesota; and Bottineau, North Dakota. An inspection of these figures suggest that the timing of the onset and ablation of a snowpack at each station is associated with abrupt changes that occur in the DTR. The demise of the spring snowpack at each station coincides very closely with a large rise in the value of the DTR. Physically, the loss of the snowpack at this time in the annual cycle would likely lead to greatly increased maximum temperatures because of the increased receipt of solar radiation by the earth's surface. Such an increase in the maximum temperature would lead to significant increases in the DTR.

The relationship between the demise of the snowpack and the upturn of the DTR is robust even on climatological time-scales and across large spatial scales. Fig. 12 shows contours representing the Julian day on which the probability of a snow cover falls below 30\% for a given location. These probabilities are based on a 30 yr period of record from 1961 to 1990. The contours are generated by interpolating the $30 \%$ snow cover probability date at 44 stations using an inverse distance-squared interpolation procedure. The large numbers plotted on the map indicate the Julian day on which the DTR begins its spring magnitude increase. The correspondence between the end of the climatological snow cover season and the increase in the DTR is apparent across the northern Great Plains. As the snow cover recedes toward the north from late February through early April, the DTR begins its rise in concert with it. Thus, it appears that the northward retreat of the snowpack results in a general upturn in the DTR across areas of ephemeral snow cover. Schwartz (1996) suggests that this rise in the DTR is at least partially halted by increases in plant transpiration and attendant lower tropospheric water vapor content at the time of phenological 'green-up' (Schwartz 1996).

In each of the locations represented in Fig. 11, the magnitude of the DTR begins to decrease during the autumn season. At Cooperstown, this decrease occurs in an abrupt manner (Fig. 11a), while at the other stations the decrease in the DTR is more gradual. An inspection of Fig. 11 indicates that the initiation of the

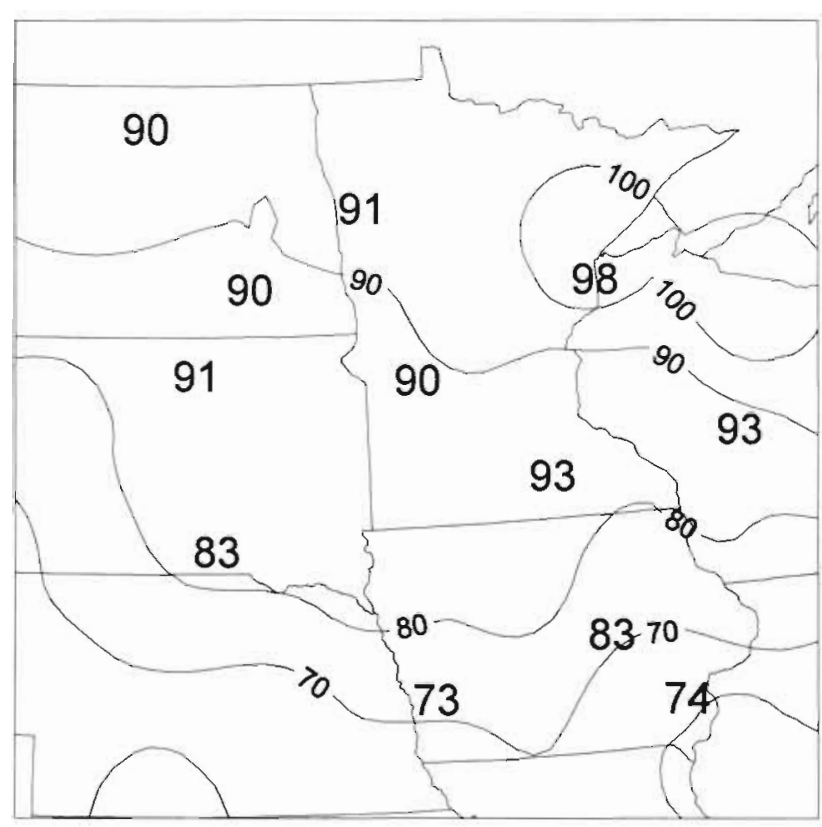

Fig. 12. Map of north central United States showing relationship between snow cover retreat and day of spring upturn in DTR. Contours show Julian day when snow cover probability falls below $30 \%$ and large numbers indicate Julian day of the onset of the upturn in the DTR

winter snowpack occurs at all locations after the onset of the DTR decrease. Thus, the introduction of a snow cover is certainly not the sole cause of the autumnal decrease in the DTR. Instead, an increase in cloud cover across the northern tier of the country, observed in our data set, seems to be the best explanation for the onset of the autumnal DTR decrease. This decrease is likely accentuated by the establishment of a snow cover later in the season. This analysis suggests, similar to Ruschy et al. (1991), that snow cover plays an important role in the rise of the DTR during the spring in the northern United States. However, its influence during the autumn season is overwhelmed by the radiative effects of increased cloud cover.

\section{SUMMARY AND CONCLUSIONS}

Although the DTR is a variable that has been studied by numerous researchers in the context of the global warming debate, few studies have focussed on the mechanisms responsible for the mean spatial and temporal characteristics of the DTR. In this study, the average annual cycle of the DTR was studied in detail for a suite of stations homogeneously distributed across the coterminous United States. Major findings from this study include the following: 
(1) The annual cycle of the DTR across the United States varies both spatially and temporally. Moreover, in many areas the DTR undergoes abrupt changes in magnitude at specific times within the annual cycle (Ruschy et al. 1991).

(2) A regionalization of the DTR resulted in the definition of 3 major DTR annual cycle regions across the coterminous United States (Fig. 3). One region encompasses the entire northern tier of the country from Maine, westward to Washington and then south along the Pacific Coast. In this region, the DTR annual cycle is characterized by maximum values during the high sun months and minimum values during the winter season. A second region covers the southern tier of the United States from the Southeast Coast to Texas. In this region the DTR reaches maximum values during the low sun months and is smallest during the summer season. Between these 2 regions lies a third that is characterized by a double peak in maximum values of the DTR, which occur during the transition seasons. It is interesting to note that regions 1 and 3 have been found to have decreasing DTRs over the last $30 \mathrm{yr}$, while region 2 DTRs have been nearly steady or increasing over the same period (Nicholls et al 1996). This may indicate that the mechanisms causing DTR change over time in regions 1 and 3 are not important in region 2, because the mechanisms responsible for the average seasonal cycle of DTR are different in this area.

(3) Annual cycles of the DTR are associated with variables that represent, in one manner or another, the moisture content of the atmosphere. The association between cloud cover and the DTR is strongest in the western United States, especially the Great Basin region. Cloud cover is also moderately associated with the DTR in the Great Lakes and the northeast United States, while the weakest associations are found across the southern portions of the Great Plains, especially in Texas. When dew point temperature is considered, the pattern of association is very similar to that observed for cloud cover. The relationship between the DTR and precipitation frequency is quite weak across the entire United States except for the area west of the Rocky Mountains.

(4) The association between the maximum and minimum temperature and the DTR is complicated both spatially and temporally. At some locations in the extreme northern portion of the country the relationship takes the shape of an upward turned parabola and the association is moderately strong. Across the northern and western portions of the United States, the relationship has a positive linear character, and the association is moderate to strong.
In much of the middle and southern United States, the relationship between the DTR and maximum and minimum temperatures is downward parabolic and relatively weak, indicating that the highest DTR is reached at intermediate temperatures.

(5) Snow cover appears to be important in an abrupt rise in the magnitude of the DTR during the spring season in many northern locations. As the snow cover leaves an area, changes in the surface energy budget lead to an increase in maximum temperatures which increase the DTR. During the autumn season, the accumulation of snow cover typically occurs after the onset of a drop in the DTR in the northern United States. This DTR drop is associated with an increase in cloud cover. Thus, the influence of the snow cover on the autumn season DTR is overwhelmed by changes in the cloud cover climatology

This study has documented the complicated nature of the average annual cycle of the DTR in the United States and some of the climate system mechanisms responsible for observed interannual variations in the DTR. The DTR range is associated with a host of climate system variables that are themselves highly related to one another. Therefore, the attribution of an interannual trend in the DTR to a single climate system cause is problematic at best. A detailed study is in progress to examine observed long-term DTR changes in the United States with the same daily temperature resolution which was utilized in this study. Increased understanding of the dynamics of the average annual cycle of the DTR gained in this study should be helpful in fully utilizing the DTR as an indicator of long-term global environmental change.

Acknowledgements. The authors thank Andrew Ellis of Arizona State University for his assistance and input on this project. This research was funded by the U.S. Department of Energy's (DOE) National Institute for Global Environmental Change (NIGEC) through the NIGEC Great Plains Regional Center at the University of Nebraska-Lincoln (DOE Cooperative Agreement No. DE-FC03-90ER61010). Financial support does not constitute an endorsement by DOE of the views expressed in this article.

\section{LITERATURE CITED}

Baker CB, Quayle RG, Wanlin W (1995) The influence of night time cloud cover on the observed minimum temperature in China. Atmos Res 37:27-35

Baker DG, Ruschy DL, Skaggs RH, Wall DB (1992) Air temperature and radiation depressions associated with a snow cover. J Appl Meteorol 31:247-255

Cao HX, Mitchell JFB, Lavery JR (1992) Simulated diurnal range and variability of surface temperatures in a global climate model for present and doubled $\mathrm{CO}_{2}$ climates. J Clim 5:920-943 
Cattell RB (1966) The scree test for the number of factors. Multivar Behav Res 1:245-276

Cayan DR, Douglas AY (1984) Urban influences on surface temperatures in the southwestern United States during recent decades. J Clim Appl Meteorol 23:1520-1530

Frich $P$ (1994) Observed trends in the diurnal temperature range in the North Atlantic region. In: Asymmetric change of daily temperature range. Proceedings of the International MINIMAX Workshop, College Park, Maryland. US Dept of Energy, Washington, DC, p 109

Gall R, Young K, Schotland R, Schmitz J (1992) The recent maximum temperature anomalies in Tucson: are they real or an instrumental problem? J Clim 5:657-665

Gallo KP, Easterling DR, Peterson TC (1996) The influence of land use/land cover on climatological values of the diurnal temperature range. J Clim 9:2941-2944

Hansen JE, Sato M, Reudy R (1995) Long term changes of the diurnal temperature cycle: implications about mechanisms of global climate change. Atmos Res 37:175-209

Jones PD, Groisman PY, Coughlan M, Plummer N, Wang WC, Karl IR (1990) Assessment of urbanization effects in time series of surface air temperature over land. Nature 347 : $169-172$

Jones PD (1995) Maximum and minimum temperature trends in Ireland, Italy, Thailand, Turkey and Bangladesh. Atmos Res 37:67-78

Kaas E, Frich P (1995) Diurnal temperature range and cloud cover in the Nordic Countries: observed trends and estimates for the future. Atmos Res 37:211-228

Karl TR, Diaz HF, Kukla G (1988) Urbanization: its detection and effect in the United States climate record. J Clim 1 1099-1123

Karl TR, Heim R Jr, Quayle RG (1991 b) The greenhouse effect in central North America: if not now, when? Science 251 1058-1061

Karl TR, Jones PD (1989) Urban bias in area-averaged surface air temperature trends. Bull Am Meteorol Soc 70:265-270

Karl TR, Jones PD, Knight RW, Kukla G, Plummer N, Razuvayev V, Gallo K, Lindseay J, Charlson RJ, Peterson TC (1993) A new perspective on recent global warming: asymmetric trends of daily maximum and minimum temperature. Bull Am Meteorol Soc 74:1007-1023

Karl TR, Kukla G, Gavin J (1984) Decreasing diurnal temperature range in the United States and Canada from 1941-1980. J Clim Appl Meteorol 23:1489-1504

Karl TR, Kukla G, Gavin J (1987) Recent temperature changes during overcast and clear skies in the United States. J Clim Appl Meteorol 26:698-711

Karl TR, Kukla G, Razuvayev V, Changery MJ, Quayle RG, Heim Jr, Easterling DR, Fu CB (1991a) Global warming: evidence for asymmetric diurnal temperature change.

Editorial responsibility: Laurence Kalkstein,

Newark, Delaware, USA
Geophys Res Lett 18:2253-2256

Kattenberg A, Giorgio F, Grassl H, Meehl GA, Mitchell JFB, Stouffer T, Tokioka T, Weaver AJ, Wigley TML (1996) Climate models - projections of future climate. In: Houghton JT, Meira Filho LG, Callander BA, Harris N, Kattenberg A, Maskell K (eds) Climate change 1995, The science of climate change. Cambridge University Press, Cambridge, p 285-358

Landsberg HE (1981) The urban climate. Academic Press, New York

Leathers DJ, Ellis AW, Robinson DA (1995) Characteristics of temperature depressions associated with snow cover across the Northeast United States. J Appl Meteorol 34 : $381-390$

Mitchell JFB, Johns TJ, Gregory JM, Tett SBF (1995) Climate response to increasing levels of greenhouse gases and sulphate aerosols. Nature 376:501-504

NCDC (1993) Solar and Meteorological Surface Observation Network (SAMSON), 1961-1990, Version 1.0. US Department of Commerce, National Climatic Data Center, Asheville, NC, and the US Department of Energy, National Renewable Energy Laboratory, Golden, CO

Nicholls N, Gruza GV, Jouzel J, Karl TR, Ogallo LA, Parker DE (1996) Observed climate variability and change. In: Houghton JT, Meira Filho LG, Callander BA, Harris N, Kattenberg A, Maskell K (eds) Climate change 1995. The science of climate change. Cambridge University Press, Cambridge, p 133-192

Plummer N, Lin Z, Torok S (1995) Recent changes in the diurnal temperature range over Australia. Atmos Res 3:79-86

Quayle RG, Easterling DR, Karl TR, Hughes PM (1991) Effects of recent thermometer changes in the cooperative station network. Bull Am Meteorol Soc 72:1718-1723

Razuvayev VN, Apasova EG, Bulygina ON, Martuganov RA (1995) Variations in the diurnal temperature range in the European region of the former USSR during the cold season. Atmos Res 37:45-51

Robinson DA (1993) Historical daily climatic data for the United States. Preprints 8th Conference on Applied Climatology, Anaheim, CA, American Meteorological Society. AMS, Boston, MA, p 264-269

Robinson DA, Leathers DJ, Palecki MA, Dewey KF (1995) Some observations on climate variability as seen in daily temperature structure. Atmos Res 37:119-131

Ruschy DL, Baker DG, Skaggs RH (1991) Seasonal variations in dally temperature ranges. J Clim 4:1211-1216

Salinger MJ (1995) Southwest Pacific temperatures: trends in maximum and minimum temperatures. Atmos Res 37 : $87-99$

Schwartz MD (1996) Examining the spring discontinuity in daily temperature ranges. J Clim 9:803-808

Submitted: March 24, 1997; Accepted: August 12, 1997

Proofs received from author(s): December 9, 1997 